\title{
META-ANALISIS PENGARUH MEDIA KOMIK DALAM MENINGKATKAN HASIL BELAJAR
}

\author{
Fefiadi Kurniawan ${ }^{1}$, Agustina Tyas Asri Hardini ${ }^{2}$ \\ Program Studi Pendidikan Guru Sekolah Dasar, Universitas Kristen Satya Wacana \\ 1292016028@student.uksw.edu, ${ }^{2}$ agustina.hardini@uksw.edu
}

\begin{abstract}
Abstrak. Penelitian ini bertujuan untuk menganalisis kembali pengaruh media komik dalam meningkatkan hasil belajar. Media adalah alat komunikasi yang digunakan untuk menyampaikan pesan atau informasi dari pengirim ke penerima. Media pembelajaran memiliki beberapa macam salah satunya media komik. Komik merupakan kumpulan gambar berwarna berisikan tokoh-tokoh yang memerankan sebuah cerita. Gambar berwarna tersebut disertai teks pendukung untuk menjelaskan alur cerita sehingga komik mudah dipahami isi ceritanya. Didalam pendidikan, media komik digunakan untuk mempermudah guru dalam menyampaikan materi kegiatan pembelajaran kepada siswa. Pada penelitian ini peneliti menggunakan penelitian meta analisis. Tahapan awal yang dilakukan adalah merumuskan masalah penelitian dan mengumpulkan data dengan melakukan penelusuran pada google scholar. Dari penelusuran didapatkan 15 artikel yang berkaitan dengan penelitian ini. Berdasarkan hasil analisis, terdapat pengaruh media komik dalam meningkatkan hasil belajar dengan presentase terendah $6,1 \%$ sampai yang tertinggi $44 \%$ dengan rata-rata peningkatan sebesar $18,46 \%$. Hasil effect size menunjukkan sebesar 2,77, hal ini menunjukkan bahwa dengan menggunakan media komik memiliki pengaruh yang besar terhadap hasil belajar siswa.
\end{abstract}

Kata Kunci: Media Komik, Hasil Belajar

\section{PENDAHULUAN}

Setiap satuan pendidikan melakukan perencanaan dan pelaksanaan pembelajaran serta memberikan penilaian pada pembelajaran dalam meningkatkan ketercapaian kompetensi lulusan. Guru memiliki peran dalam merencanakan proses pembelajaran agar terwujudnya suasana belajar yang tepat untuk siswa. Menurut Djamarah (2011:13) belajar adalah kegiatan seseorang dalam mendapatkan perubahan tingkah lakunya yang dianggap sebagai hasil dari pengalaman seseorang dalam melakukan interaksi dengan lingkungan yang menyangkut hasil kognitif, afektif, dan psikomotorik.

Untuk meningkatkan hasil belajar diperlukan inovasi dalam kegiatan pembelajaran berlangsung salah satunya dengan menggunakan media pembelajaran. Dengan adanya media pembelajaran, kegiatan pembelajaran dapat berjalan dengan efektif dalam mencapai tujuan pembelajaran. Kegiatan pembelajaran yang efektif dan inovatif diperlukan agar siswa dapat berperan aktif selama pembelajaran dan guru harus menggunakan media yang sesuai dengan materi yang akan disampaikan agar tercapainya tujuan pendidikan.

Munadi (2013:100) menjelaskan bahwa komik merupakan gambar yang berbentuk kartun dan didalamnya terdapat urutan cerita yang disajikan secara ringkas dan mudah. Media memiliki beberapa macam, menurut Sadiman (2008:28) macam-macam media pembelajaran, antara lain : 1. Media Grafis (media visual seperti gambar/foto, sketsa, diagram, bagan/chart, grafik, kartun, poster, peta, serta globe), 2. Media Audio yang terkait dengan indera pendengaran (radio, dll), 3. Media Proyeksi Diam (film frame (slide), film buat (film strip), media transparan, film, tv, video).

Komik merupakan salah satu bagian dari media, menurut Sudjana dan Rivai (2013:68) Komik adalah suatu bentuk bacaan di mana 
Jurnal Ilmu Sosial dan Pendidikan

http://ejournal.mandalanursa.org/index.php/JISIP/index

Terakreditasi Peringkat 5 (No. SK: 85/M/KPT/2020)

siswa membacanya tanpa harus dibujuk. Menurut Daryanto (2010:139-140) komik memiliki kelebihan, antara lain : 1) Menambah kemampuan membaca siswa serta penguasaan kosakata yang jauh lebih banyak, 2) Penyajiannya yang mengandung unsur visual dan cerita yang kuat sehingga pembaca dapat terbawa suasana ketika membaca komik. Dari kelebihan inilah komik dibuat dengan berisikan materi pelajaran agar siswa lebih suka dalam membaca dan belajar dibandingkan dengan buku teks yang tidak bergambar serta tidak mengandung ilustrasi yang menarik.

Hal ini didukung oleh penelitian terdahulu, seperti menurut Arnelia Dwi Yasa, dkk (2018) Terdapat pengaruh penggunaan media komik pembelajaran terhadap hasil belajar tematik siswa kelas V SD. Menurut Wina Maisafni Dunita, dkk (2019) Terdapat perbedaan hasil belajar setelah menerapkan media komik pada pembelajaran PKn peserta didik kelas III SDN 27 Koto Baru Kabupaten Pesisir Selatan. Menurut Fitri Apriyanti, dkk (2012) Terdapat pengaruh yang besar terhadap tingginya hasil belajar siswa kelas V SDN 24 Pontianak Tenggara.

Beberapa penelitian yang telah dilakukan menyasar bidang kajian di berbagai jenjang pendidikan, wilayah dan beberapa mata pelajaran. Namun, sampai saat ini belum ada penelitian meta-analisis terbaru khususnya mengenai pengaruh media komik dalam meningkatkan hasil belajar. Maka berdasarkan permasalahan yang telah ditampilkan, peneliti hendak melakukan penelitian tentang "MetaAnalisis Penggunaan Media Komik terhadap Hasil Belajar".

\section{METODE PENELITIAN}

Penelitian ini menggunakan penelitian meta analisis. Menurut Wahyuningsih, dkk (2019:33) meta analisis adalah suatu penelitian yang menganalisis berbagai penelitian yang mengarah pada pembahasan masalah yang sama untuk mendapatkan kesimpulan bersifat umum secara luas. Tahapan awal yang dilakukan
Vol. 4. No. 4 November 2020

p-ISSN: 2598-9944 e- ISSN: 2656-6753 peneliti dengan mencari dan menelusuri setiap artikel-artikel yang ada didalam jurnal dan skripsi melalui penelusuran pada Google Scolaria. Kata kunci yang digunakan oleh peneliti pada saat melakukan penelusuran adalah "Meta Analisis", "Hasil Belajar". Dari proses penelusuran yang telah dilakukan oleh peneliti dengan menggunakan kata kunci "Meta Analisis", "Hasil Belajar" diperoleh beberapa artikel yang memenuhi kriteria penelitian yang akan digunakan, terdapat data sebelum diberikan perlakuan dan sesudah diberikan perlakuan dalam bentuk skor persentase rata-rata. Instrumen data yang digunakan adalah pemberian kode masing-masing artikel yang didapatkan.

Teknik analisis data menggunakan metode pembanding untuk menentukan pengaruh media komik dalam meningkatkan hasil belajar. Analisis yang digunakan dalam penelitian ini adalah membandingkan selisih skor sebelum menggunakan media komik dan sesudah menggunakan media komik dalam bentuk presentase (\%) untuk menentukan besarnya pengaruh media komik dalam meningkatkan hasil belajar.

\section{HASIL DAN PEMBAHASAN}

Dari hasil penelitian yang dilakukan oleh peneliti, maka diperoleh sebanyak 15 artikel terkait dengan pengaruh media komik dalam meningkatkan hasil belajar siswa sekolah dasar. Data yang diperoleh kemudian diolah dengan cara merangkum hasil penelitian. Data yang diperoleh kemudian dimasukkan kembali secara deskriptif kualitatif dan kuantitatif. Data dari hasil dari analisis media komik dapat dilihat sebagai berikut : 
Jurnal Ilmu Sosial dan Pendidikan

http://ejournal.mandalanursa.org/index.php/JISIP/index

Terakreditasi Peringkat 5 (No. SK: 85/M/KPT/2020)

Tabel 1. Persentase Peningkatan Hasil Belajar Siswa dengan Media Komik

\begin{tabular}{|c|c|c|c|c|}
\hline \multirow{2}{*}{ No. } & \multirow{2}{*}{$\begin{array}{l}\text { Kode } \\
\text { Data }\end{array}$} & \multicolumn{3}{|c|}{ Presentase } \\
\hline & & Pretest & Posttest & Peningkatan \\
\hline 1. & P1 & 59 & 81,2 & 22.2 \\
\hline 2. & P2 & 54.5 & 78 & 23.5 \\
\hline 3. & P3 & 31,71 & 75,71 & 44 \\
\hline 4. & P4 & 73,243 & 85,676 & 12,433 \\
\hline 5. & P5 & 64,08 & 77,42 & 13.34 \\
\hline 6. & P6 & 50,32 & 86,13 & 35.18 \\
\hline 7. & P7 & 68,62 & 85,24 & 16.62 \\
\hline 8. & P8 & 63,70 & 78,37 & 14.67 \\
\hline 9. & P9 & 69 & 76 & 7 \\
\hline 10. & P10 & 60,23 & 83,57 & 23.34 \\
\hline 11. & P11 & 53,227 & 72,795 & 19.568 \\
\hline 12. & P12 & 84,52 & 90,62 & 6,1 \\
\hline 13. & P13 & 55,06 & 75,35 & 20.29 \\
\hline 14. & P14 & 62,89 & 71,17 & 8.28 \\
\hline 15. & P15 & 71,19 & 80,95 & 9,76 \\
\hline & rata & 61.42 & 79.88 & 18,46 \\
\hline
\end{tabular}

Tabel 1 menunjukkan bahwa data sebelum dan sesudah penggunaan media komik terdapat adanya perbedaan pada skor rata-rata yaitu sebelum dan sesudah digunakannya media komik dalam meningkatkan hasil belajar siswa sekolah dasar. Pada persentase rata-rata peningkatan hasil belajar siswa dengan menggunakan media komik mulai dari yang terendah $6,1 \%$ hingga pada yang tertinggi $44 \%$ dengan angka rata-rata $18,46 \%$. Rata-rata nilai hasil belajar siswa sebelum menggunakan media komik adalah $61,42 \%$ dan kemudian mengalami peningkatan yang signifikan yaitu menjadi $79,88 \%$. Berikut ini adalah diagram gambar sebelum dan sesudah menggunakan media komik

Diagram 1 . Peningkatan Sesudah dan Sebelum Menggunakan Media pembelajaran komik

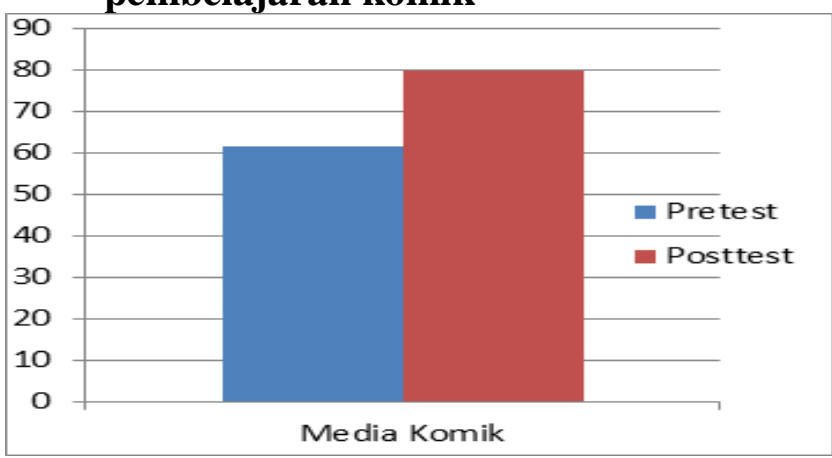

Vol. 4. No. 4 November 2020

p-ISSN : 2598-9944 e- ISSN: 2656-6753
Diagram 1 menunjukkan bahwa terdapat peningkatan dari skor sebelum ke sesudah menggunakan media komik yaitu sebelum digunakan hasil belajar pada siswa Sekolah Dasar hanya mencapai $61,42 \%$ saja dan setelah digunakan media komik rata-rata hasil belajar siswa mengalami peningkatan yang signifikan yaitu mencapai $79,88 \%$, jadi dapat disimpulkan bahwa rata-rata hasil belajar siswa SD meningkat sebesar $18,46 \%$.

Tabel 2. Uji Normalitas Media komik

\begin{tabular}{|c|c|c|c|c|c|c||}
\hline & \multirow{2}{*}{ Kelas } & \multicolumn{2}{|c|}{ Kolmogorov-Smirnova } & \multicolumn{2}{|c||}{ Shapiro-Wilk } \\
\cline { 3 - 6 } & & Statistic & df & Sig. & Statistic & df \\
\hline \multirow{3}{*}{ Hasil Belajar } & & & & & \\
\hline & Pretest &, 116 & 15 &, $200^{\circ}$ &, 957 & 15 \\
& Posttest &, 113 & 15 &, $200^{*}$ &, 979 & 15 \\
\hline
\end{tabular}

Tabel 2 menunjukkan bahwa uji normalitas hasil belajar skor pretest dan posttest menggunakan media komik dapat dikatakan jika diperoleh nilai Sig. $<0,05$ maka data berdistribusi tidak normal dan jika nilai Sig. > 0,05 maka data berdistribusi normal.

1. Tingkat Sig. skor pretest media komik adalah $0,130>0,05$ artinya nilai berdistribusi normal.

2. Tingkat Sig. skor posttest media komik adalah $0,853>0,05$ artinya nilai berdistribusi normal.

\section{Tabel 3 . Paired Samples Statistics}

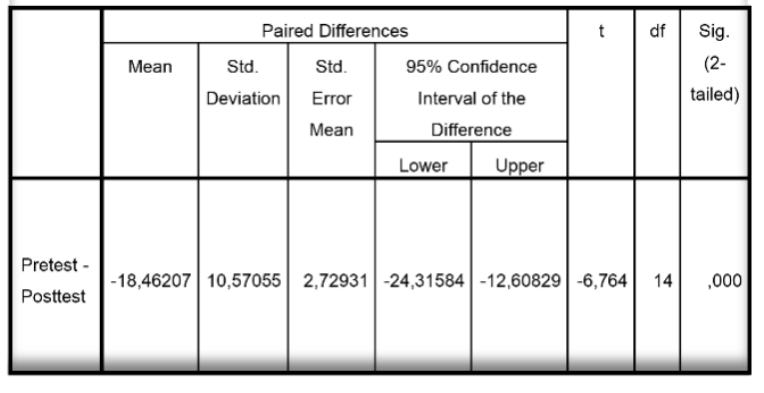

Tabel 3 menunjukkan bahwa pembelajaran dengan menggunakan media komik mempunyai pengaruh yang sangat besar dalam meningkatkan hasil belajar siswa sekolah dasar. Pada nilai rata-rata pretest menggunakan media komik menunjukkan angka yaitu sebesar 
Jurnal Ilmu Sosial dan Pendidikan

http://ejournal.mandalanursa.org/index.php/JISIP/index

Terakreditasi Peringkat 5 (No. SK: 85/M/KPT/2020)

61,4180. Kemudian sesudah menggunakan media komik nilai posttest mengalami kenaikan yaitu 79,8801. Dari jumlah skor menunjukkan adanya perubahan yang signifikan sehingga membuktikan bahwa dengan menggunakan media komik dapat membantu dalam meningkatkan hasil belajar siswa di sekolah dasar.

\section{Tabel 4. Uji Paired Samples Correlations}

\begin{tabular}{|ll|c|c|c|}
\hline & N & Correlation & Sig. \\
\hline Pair 1 & $\begin{array}{l}\text { Pretest \& } \\
\text { Posttest }\end{array}$ & 15 &, 492 &, 062 \\
\hline
\end{tabular}

Tabel 4 menunjukkan bahwa nilai Sig yaitu $0,062>0,05$. Sehingga dapat disimpulkan bahwa tidak terdapat hubungan antara variabel pretest dan posttest dikarenakan >0,05.

\section{Tabel 5. Uji Paired Samples Test}

\begin{tabular}{|c|c|c|c|c|c|c|c|c|}
\hline & \multicolumn{5}{|c|}{ Paired Differences } & \multirow[t]{3}{*}{$t$} & \multirow[t]{3}{*}{$\mathrm{df}$} & \multirow{3}{*}{$\begin{array}{l}\text { Sig. } \\
(2- \\
\text { tailed) }\end{array}$} \\
\hline & \multirow[t]{2}{*}{ Mean } & \multirow[t]{2}{*}{$\begin{array}{c}\text { Std. } \\
\text { Deviation }\end{array}$} & \multirow[t]{2}{*}{$\begin{array}{l}\text { Std. } \\
\text { Error } \\
\text { Mean }\end{array}$} & \multicolumn{2}{|c|}{$\begin{array}{l}95 \% \text { Confidence } \\
\text { Interval of the } \\
\text { Difference }\end{array}$} & & & \\
\hline & & & & Lower & Upper & & & \\
\hline $\begin{array}{l}\text { Pretest - } \\
\text { Posttest }\end{array}$ & $-18,46207$ & 10,57055 & 2,72931 & $-24,31584$ & $-12,60829$ & $-6,764$ & 14 & ,000 \\
\hline
\end{tabular}

Tabel 5 menunjukkan bahwa pada kolom Sig. (2-tailed) sebesar 0,000 yang berarti lebih kecil dari $0,05(0,000<0,05)$ yang berarti bahwa $\mathrm{H}_{\mathrm{o}}$ ditolak dan $\mathrm{H}_{\mathrm{a}}$ diterima. Selain itu, dapat dilihat thitung sebesar $-6,764$ dan $t_{\text {tabel }}$ yang diperoleh sebesar 1,77093. Berdasarkan dari hasil proses penghitungan yang dilakukan oleh peneliti maka dapat dilihat pada tabel di atas menunjukkan terdapat perbedaan yang signifikan dalam meningkatkan hasil belajar siswa sekolah dasar sebelum menggunakan media komik.

Berdasarkan hasil data penelitian diatas menunjukkan bahwa pada hasil penelitian selalu terdapat presentase hasil peningkatan belajar yang berbeda-beda. Peneliti menemukan bahwa terdapat beberapa faktor yang mempengaruhi hasil penelitian yang dilakukan yaitu faktor yaitu faktor internal dan faktor eksternal. Sejalan dengan Isnaini Wijayani dalam Dalyono
Vol. 4. No. 4 November 2020

p-ISSN : 2598-9944 e- ISSN: 2656-6753
(2017:14) mengemukakan bahwa terdapat 2 faktor yang mempengaruhi hasil belajar siswa, yaitu : 1). faktor internal yang meliputi kesehatan, intelegensi , bakat, minat, motivasi, dan cara belajar, 2). faktor eksternal yang meliputi lingkungan keluarga, sekolah, masyarakat, dan lingkungan sekitar. Selain faktor internal dan eksternal, tempat dilakukannya penelitian juga mempengaruhi hasil, dimana pada setiap daerah mempunyai tingkat kemampuan siswa yang berbeda. Muatan dalam pembelajaran juga dapat mempengaruhi hasil penelitian, hal ini tergantung dari isi materi yang disampaikan. Cara guru dalam menyampaikan pembelajaran juga berbedabeda antara guru A dan guru B meskipun menggunakan media pembelajaran yang sama hal inilah yang menyebabkan adanya perbedaan pada hasil belajar.

\section{KESIMPULAN}

Berdasarkan hasil penelitian meta analisis dapat disimpulkan bahwa pembelajaran dengan media komik sangat berpengaruh dalam meningkatkan hasil belajar siswa sekolah dasar. Hal ini dapat dilihat dari hasil uji Paired Samples Test yang menunjukan nilai signifikan yaitu $0,000<0,05$ sehingga terdapat perbedaan yang signifikan pada peningkatan hasil belajar siswa sekolah dasar sebelum dan sesudah menggunakan media komik.

\section{SARAN}

Setelah dilakukannya penelitian, maka saran dari peneliti yaitu :

1. Bagi guru media komik dapat dijadikan sabagai salah satu alternative dalam pembelajaran dikelas.

2. Bagi peneliti diharapkan supaya lebih lengkap dalam mencantumkan data penelitian.

\section{UCAPAN TERIMA KASIH}

Puji syukur peneliti panjatkan kepada kehadirat Tuhan Yang Maha Esa karena atas 
berkat rahmat dan hidayah-Nya sehingga peneliti dapat menyelesaikan penelitian ini.

Dalam menyelesaikan penelitian ini peneliti menyadari banyak mengalami kesulitan yang dihadapi baik dari segi waktu, biaya, maupun tenaga. Akan tetapi kesulitan dan hambatan itu dapat dilalui dengan usaha, keteguhan dan kekuatan hati, dorongan kedua orangtua yang begitu besar, dan partisipasi dari berbagai pihak. Penelitian ini dapat terselesaikan walaupun masih jauh dari kata kesempurnaan. Untuk itu kritik dan saran yang bersifat membangun dari pembaca sangat diharapkan demi kesempurnaan penelitian ini.

Akhir kata peneliti juga tidak lupa untuk mengucapkan terima kasih kepada pihak yang telah membantu dalam menyelesaikan artikel ini dan semoga artikel ini bermanfaat bagi kita semua.

\section{DAFTAR PUSTAKA}

Apriyanti, F., Margiati, K. Y., \& Kartono, K. (2012). Pengaruh Pemanfaatan Media Komik Matematika terhadap Hasil Belajar Kelas V SDN 24 Pontianak Tenggara (Doctoral Dissertation, Tanjungpura University).

Dunita, W. M., \& Asril, Z. (2019). Pengaruh Media Komik terhadap Hasil Belajar PKN Peserta Didik Kelas III SD Negeri 27 Koto Baru Kabupaten Pesisir Selatan. Tarbiyah Al-Awlad, 9(1), 8598.

Juliandri, J., \& Anugraheni, I. (2020). Meta Analisis Model Pembelajaran Problem Based Learning untuk Meningkatkan Hasil Belajar Siswa SD. Pedagogy, 7(2), 21-27.

Karmila, B., \& Mawardi, M. (2020). Meta Analisis Efektifitas Model Pembelajaran Team Games Tournamen (TGT) dan Model Pembelajaran Numbered Head Together (NHT) Terhadap Peningkatan Keterampilan Kolaborasi Siswa SD. Jisip (Jurnal Ilmu Sosial Dan Pendidikan), 4(4).
Maryani, Y. (2020). Pengembangan Komik Sebagai Media Pembelajaran Teks Biografi dalam Upaya Meningkatkan Minat Baca Pada Siswa Kelas X Smkn 3 Bandung. Wistara: Jurnal Pendidikan Bahasa Dan Sastra, 3(1), 45-49.

Rohmasari, D. N. (2019). Pemanfaatan Kemasan Produk sebagai Media Pembelajaran Matematika Manipulatif.

Rohmawati Fajrin, E. (2016). Pengaruh Penggunaan Media Komik terhadap Hasil Belajar Siswa Kelas Iv Pada Tema Indahnya Negeriku di Sekolah Dasar. Jurnal Penelitian Pendidikan Guru Sekolah Dasar, 3(2).

Susanti, D. (2016). Pengaruh Penerapan Metode Inkuiri terhadap Hasil Belajar Matematika pada Siswa Kelas V SD Negeri 1 Rajabasa Raya Bandar Lampung Tahun Pelajaran 2015/2016.

Wijayani, I. (2017). Hubungan Motivasi Belajar dengan Prestasi Belajar Siswa Kelas V SD Negeri 1 Waringinsari Barat Kabupaten Pringsewu.

Yasa, A. D., \& Chrisyarani, D. D. (2018, October). Pengaruh Media Komik Tematik terhadap Hasil Belajar Siswa Kelas V SD. In Prosiding Seminar Nasional Multidisiplin (Vol. 1, Pp. 9295). 